\title{
Meeting Points: \\ Choreographies of Horses and Humans
}

\author{
LYNDA BIRKE \\ University of Chester (UK)
}

\begin{abstract}
In this paper, I explore horse-human interactions as 'meeting points', using three points or places at which we come together with horses. These are: in the stable, leading a horse, and riding. Each shapes the interspecies engagement, in a kind of trajectory. Ways of engaging with each other form within the confines of stable or corral, which then continue into other activities. The idea of meeting points serves to emphasise that these are meetings with an other, someone who has agency and who helps to create the patterns of subsequent interactions. These are meetings born out of individual experience, and which help to produce the mindedness of the horse.
\end{abstract}

KEYWORDS: horse; meeting points; human-animal relationship

\section{Introduction}

We live our lives in spatial relationships with many other animals. I live in an old farmhouse in rural England, along with two dogs. Outside dwell several horses, and a group of chickens. The house also means home to a colony of long-eared bats, a multitude of invertebrates, various swallows, martins, barn owls, sparrows, wrens and blue tits - and no doubt more rats and mice than I care to think about. Human-animal relationships are thus lived through sharing (or not) of spaces; we cohabit within buildings, within cities, within parks and woods. Some of those relationships are just that: cohabitation, requiring little direct interaction, although shaped and made possible by the spaces and buildings we have constructed. Others, like my relationships with the dogs and horses, seem to be more mutual, a shared choreography within those spaces. Thus, when a new dog 
arrived in the farmhouse from the rescue kennels, it took only a couple of days for dog and person to learn where the other was and to orient around each other - where are you? If I move here...? Expectancies develop such that each understands how the other moves, where they will be.

Such learning to orient around one another requires paying close attention, and is fundamental to our (sometimes) close relations with companion animals. Wild animals perhaps know where we are, but it is companion animals who seem to attend closely to what we do and say. Given our long coexistence with dogs and horses in particular, it is not surprising that these animals have abilities to recognise and pay attention to our gestures and emotions (Rochais et al. 2014; Smith et al. 2016; Albuquerque et al. 2016). If I enter the stable of one of my (familiar) horses, how we interact is shaped partly by how much we attend to one another in that moment and also by our shared histories. But it is also likely to be shaped by material things - by the halter I may have in my hand (or the food), or by the structures around us, the walls, the manger.

In this article, I explore human encounters with horses in terms of such spatialised social relations, using the idea of interspecies 'meeting points'. This paper is exploratory, drawing partly on my own experience of a lifetime of engaging with horses, but also drawing on previous research studies, which used observation and interviews to examine horse-human relationships. I use these sources to explore three ways in which human and equine bodies meet and move around one another: the spatial practices of meeting in the stable, leading alongside, and riding.

\section{Meeting points in shared spaces}

Armstrong Oma (2013) invokes the notion of 'meeting points' of human and animal. These are not necessarily synonymous with rooms, but are rather places where human and animal come together. Whether a horse lives with other horses in a corral or field, or alone in a stable, interspecies meeting points happen when the human catches the horse; once outside, horse and human share activities for a time. Boundaried spaces such as stables mould horses' experiences of engaging with us, and our experiences of them. And they provide meeting points - partial and temporary - which flow into how horses and humans relate to each other.

Our interactions with domestic animals have long flowed through constructions made by humans. In prehistoric times, people and some animals literally lived alongside each other within buildings and in pens and fields to produce "particular life-spaces ... shared by its members" (Armstrong Oma 2013, 164). Until relatively recently, horses 
lived close to humans, if not within the same building then very close byㄹ: urban life, like rural agriculture, could not function without horsepower and horses were ubiquitous (McShane and Tarr 2007; Morris 2008). Although horses have now largely moved out of cities, and today are predominantly associated with rural life, our encounters with them are usually constrained by, and shaped within, physical boundaries.

Constructions such as stables or barns are, however, more than merely containers for specific animals, or social activities. Lefebvre (1991), in his discussion of the 'construction of space' notes that when we refer to a space such as a room, or a marketplace, we generally refer to specific uses of that space - that is, specific social/spatial practices associated with it. He argues that 'spaces' are thus produced from social activity, such that 'space' is always being made and remade; in similar vein, writing about animal-human encounters in cities, Holmberg $(2015,30)$ notes that "place structures and produces social relations ... Members are not 'in' a place, but produce it through various bodily adjustments and practices".

The first meeting point thus centres on the physical spaces in which we initially approach a horse; here, I focus on the limited space of the stable or small corral in which so many horses are kept. Although the primary response of a young or a feral horse to human approach would be to flee, domesticated horses quickly learn how to read and respond to us, to create moments of meeting. They cannot easily flee far within the confines of four walls, and the boundaries necessarily force attention, ways of responding, which then shape further interactions. It is as though in the stable/corral, the walls direct the dance.

The second meeting point occurs when horse and person move together outside the stable. No longer necessarily bounded by walls, their coming-together is typically mediated by some means of leading the horse, such as a rope. Yet, over time, human and horse learn how to move together, to focus attention on the other, such that - at times - the physical connection seems irrelevant, the connection apparently occurring independently of the rope. The third meeting point is the close bodily connection afforded through riding, as horse and human take part in shared endeavours, such as trail rides and competitions.

Each of these illustrates points of connection, of meeting between horse and human. In some ways, they map a trajectory in the relationship: the bodily awareness that riders so often extol as 'feel' is an end-point of a process that perhaps began in the

1 Roman armies occupying Britain, for example, literally lived alongside their horses, in the same buildings: see http://www.english-heritage.org.uk/learn/story-of-england/romans/absence-ofstables [accessed March, 2016] 
stable, and develops further through working with each other on the ground. To work together, what horses and their people must learn is an awareness of where the other is in space; both must learn how to meet. Out of these - sometimes - we experience a sense of connection, a relationship. Perhaps they do, too, although we cannot easily tell. What we can see, however, appears to be mutuality, where human and animal behaviour becomes coordinated and interdependent (Brandt 2004; Birke \& Hockenhull 2015).

\section{Meeting Point One: Within four walls}

'Stable': the word derives originally from the Latin stabilis, meaning a place to stand. It also connotes unchanging or equilibrium. ${ }^{2}$

A horse's stable may mean many things: it may mean stability, even a place to return, a home for the horse. 'A place to stand' may be welcome to a tired horse, but it may also imply separation from others. From a human perspective, a row of stables permit regulated access to, and surveillance of, the animals. While it may be preferable for horses to live at pasture, humans often keep them individually, in smaller spaces; what is prioritised is our access and ability to control the animal's immediate environment. Horses are flight animals, easily spooked, so limiting their possibilities for flight is obviously useful to humans.

Encounters with individuals kept in these circumstances are thus often rather limited, and usually on our terms. When we enter the stable or other equine living area, we may be signalling something desirable (food, a grooming) or less desirable (work, the vet) - though the horse usually has little choice but to pay attention to us ${ }^{3}$. Interspecies social engagements are thus structured around human schedules, and the encounter dictated by the limited physical space.

Individual stables may be in a block, with horses able to look out at a central yard (a layout typical in the racing industry in Britain, for instance), or, they may be internal boxes formed by partitioning within a larger barn. My focus here is on these individual stables as specific structures which shape how we and horses share space, albeit

2 http://www.oxforddictionaries.com/definition/english/stable [accessed March, 2016]

3 Not all horses, of course, are housed individually in stables - much depends on human finances, and attitudes. I focus here on stables, largely because the horses who were the focus of my research were all housed in stables or small corrals, and that has been the case for the horses I have encountered personally. However, the point about how husbandry spaces limit and constrain how we engage with animals is a more general one. 
partially. The historic separation of stable blocks from human habitation (especially in the case of well-to-do houses) did not necessarily mean that horses were not sharing space with humans. On the contrary, typical stable blocks in the UK had space above the horses, which provided an area for hay storage, as well as living accommodation for grooms (there are two of these large spaces at our farm; today, they house mostly bats, owls and house martins). Thus,'stables', as separate buildings from main houses, materialised particular kinds of interhuman relations (through social class), but also of interspecies relations (through the segregation of these animals from some of the human living accommodation).

Stabling horses means enclosing them within barriers for periods of time. Humans may, or may not, move in and out of this physical space at different times. How we keep horses, and make priorities around equine husbandry, depend upon many factors - economics, the purpose for which the horse is kept, as well as what might be termed equestrian cultures (Latimer \& Birke 2009). What is prioritised in choosing to house horses in stables is human access and ability to control the animal's immediate environment; interspecies social engagements are thus shaped by where they occur.

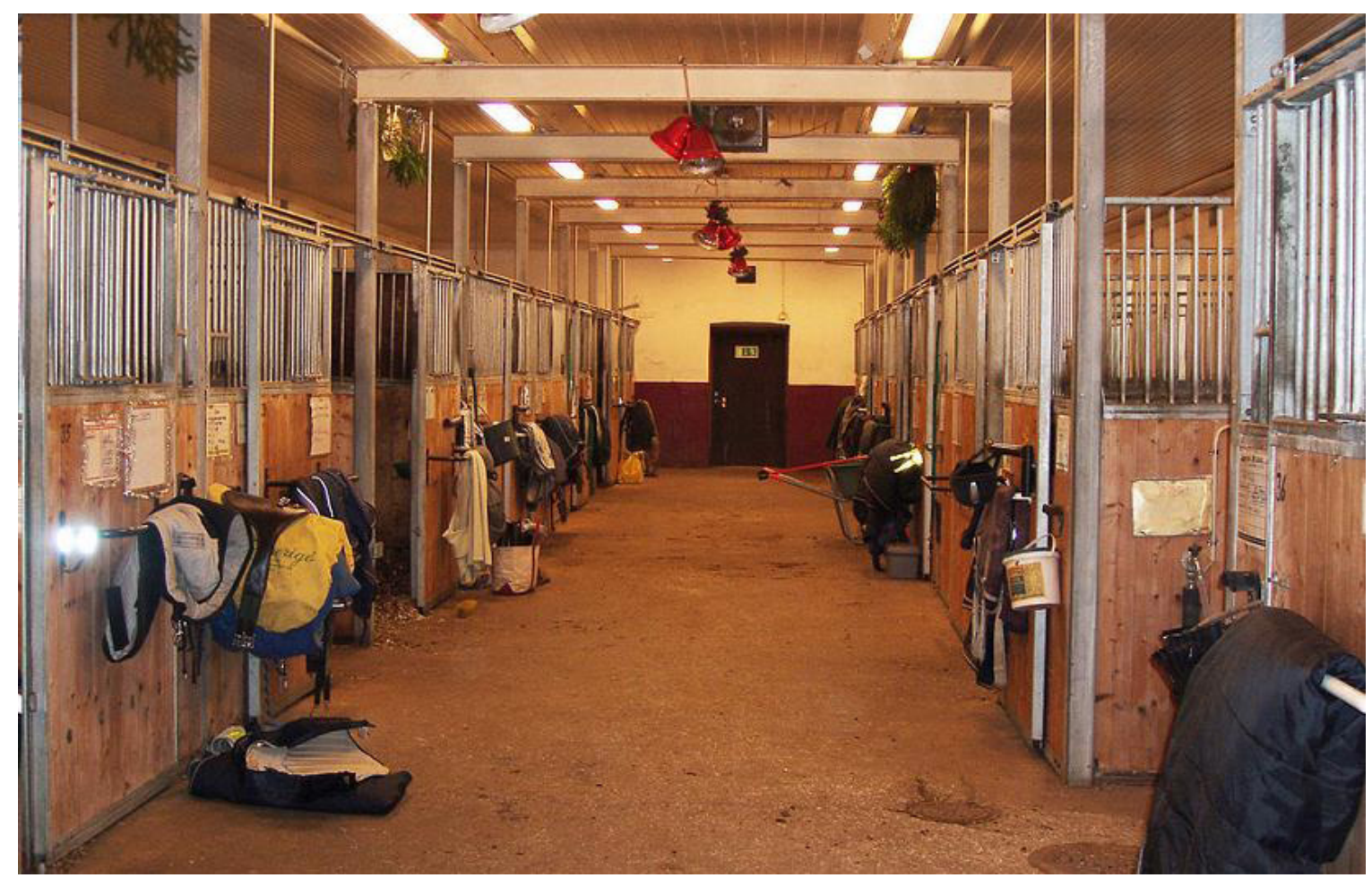

Figure 1: Stabling in a barn in Sweden (photograph by user Lidingo, shared under Creative Commons licence at https://en.wikipedia.org/wiki/Stable) 
Figure 1 shows stabling inside a barn. Several loose boxes are situated either side of a central aisle, each with various bits of equestrian paraphernalia - saddles, rugs, buckets, brushes, identifying labels. The horses themselves are not obviously present; perhaps they are all out being ridden. Each horse's stable is separated by a partition, although these partitions are topped with bars; horses can therefore see and smell each other even if they are unable to interact directly. They are, however, at the beck and call of their human guardians, who will determine when and how they will meet, or leave the stable. The central aisle of the barn, moreover, permits surveillance at a glance, and channels activity, as horses are led in and out for grooming, riding and other activities.

These structures produce a spatiotemporal ordering of activities and bodies, in which both humans and horses must learn to navigate. The limited space of the aisled block means that horses must 'learn discipline' (see Latimer \& Birke 2009), to learn to behave spatially around humans. People, too, must learn spatial awareness around horses in these confined spaces; novice riders are often less able either to predict the horse's actions or to prevent the horse from barging into them.

Stables thus provide physical structures which contain and produce horse-human encounters. If I enter a stable, even that of a horse I do not know, the horse is likely to pay visual attention to me, perhaps to walk over. In that moment, I must pay attention to her body language: is she signalling interest, with her ears and eyes forward? Or do I have to move quickly as she puts her ears back and bares her teeth? There are, to be sure, opportunities for more intimate social encounters; horses find scratching and grooming pleasurable, and my time there might be spent doing just that.

Yet these social encounters are at human behest. We decide when and how we enter the stable, and we keep watch over the horses who live there. While human-horse meetings in larger areas, such as a field, mean that horses can (and do) choose to walk away, horses within stables can only choose to ignore us - for a while. We and they must necessarily pay attention to the other, and (we hope) to move around each other carefully. Four walls necessarily limit what is possible: you cannot go far circling around each other in a four meter square box. So, however much horse and human have interacted in the stable, they must also venture outside their enclosure, sometimes around other horses and people. And, as they walk around alongside each other, perhaps to the pasture, perhaps to a riding arena, their meeting point depends upon the lead-rope. 


\section{Meeting Point Two: At either end of a rope}

"... it was ... a cooperation and he was more up at my side and [it] was like we were going through it together ... it was more like joint decision making"

(interview, horse owner: Birke \& Hockenhull 2015)

If you observe a busy stable yard, you will see most horses and their people moving together around the stable yard in apparent acceptance. Occasionally, there is a disturbance - perhaps a horse startles, or misunderstands the humans' actions, and pulls away. Familiarity and experience matter, of course. Inexperienced horses, led by relatively novice handlers, often seem distracted, unsure of what is being asked of them. One handler in our research described the (novice) horse she was leading as "completely distracted, I'm not sure I would have known he was on the other end of the rope... he wasn't engaging with me at all" (see Birke \& Hockenhull 2016). The horse repeatedly pulled back, resisting her attempts to lead him quietly. In this case, the encounter seemed conflictual, and the halter and rope offered only partial control.

Yet, for much of the time, horses and humans do work alongside each other; perhaps halter and rope sometimes signal to the horse that a relationship has been activated, one with expectations - it is often difficult to lead a horse without it by, say, holding the horse's forelock hair. It is as though the halter communicates that the horse should pay attention (or perhaps simply that horses know that the rope/halter will be activated if they don't comply). ${ }^{4}$ Early training of horses involves, among other things, persuading the horse to give attention to humans, to become aware of where they are. One example of this is the training methods advocated by some 'natural horsemanship' enthusiasts, such as Monty Roberts. For starting a naive horse, Roberts utilises a round pen, which constrains the horse's movement; he then shoos the horse away until the animal begins to approach (Roberts 1997). The horse very quickly attends to human actions and location. ${ }^{5}$

4 Birke \& Michael (1997) discuss human-animal negotiations around devices such as dogleads. It is never entirely clear who is in control, and it is the "hybrid of human-doglead-dog who must negotiate ... tricky terrain" (ibid., 10). Here, we might talk of the hybridity of human-leadropehorse. In making this point, I should emphasise that leads and ropes can also be means of abuse; my focus here is on relationships where there is some degree of mutuality.

5 Roberts' own interpretation is that the handler is 'speaking' in a language the horse understands, and that the horse approaches voluntarily. This procedure stages his expertise in particular ways, and the response of the horse is open to multiple interpretations (see Schuurman \& Franklin 2015; Birke 2008). 
Horses and humans who know each other well often seem to walk calmly alongside one another as they move from point to point; their movements appear coordinated, seemingly in harmony. Such 'moving together' is partly a product of familiarisation, begun in the stable or corral. Over time, both learn how to track where the other is. If horse and human are familiar to each other, then they begin to coordinate, their moving together seems to flow; there is 'joint decision making', there is coordination. There is also mutual attention, partly visual (watching the other alongside), but also partly involving a kind of bodily awareness of the other. And this mutuality seems not to depend significantly upon any device such as a lead rope: indeed, it can seem as though the two are joined by an invisible thread (see Birke \& Hockenhull 2015).

Figure 2 shows an example of such mutuality: here, Bill and his person, R., were navigating some obstacles in an arena. Bill's lead-rope was loose. What was connecting them was not so much the rope, but an intangible connection: they knew how to read each other, and paid close attention. As a result, they moved harmoniously seemingly independent of the physical ties. Observers agreed: Bill and R., they said, 'clearly knew and trusted each other', and 'worked well together' (Birke \& Hockenhull 2015). These two illustrated how horses and humans (sometimes) work in close cooperation. In the sequence shown, both look at each other, checking where they are, attuned to one another. The rope seems irrelevant.
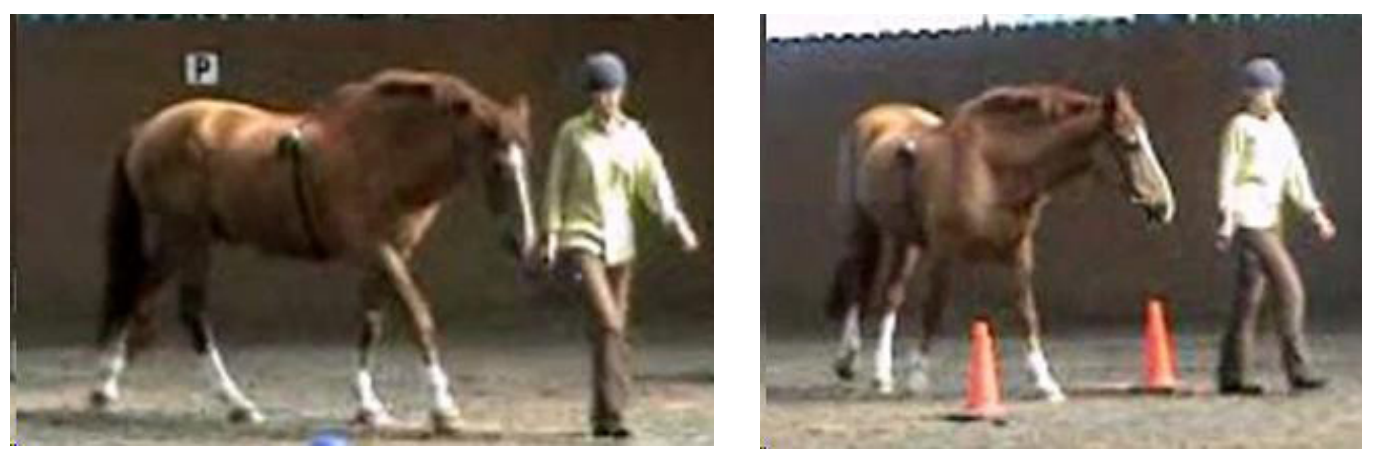

Figure 2: Bill and R, working together, paying attention to each other

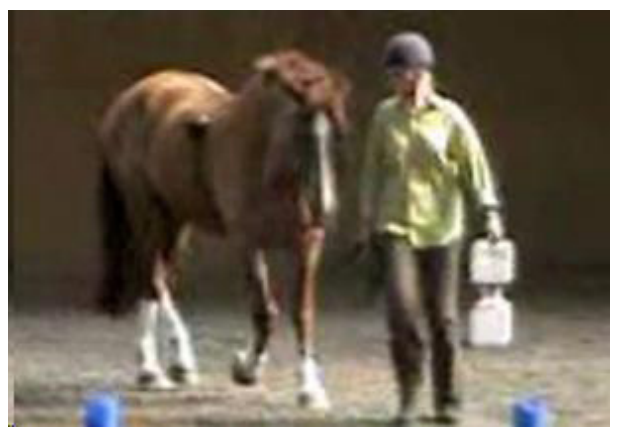


For Kez (Figure 3), the 'invisible thread' to her person remained when she was handled by someone else. Kez was clearly unhappy to be handled by strangers; what mattered to her was where her human, L., was. In the first picture, she appears tense - her ears were back, her tail swished, her head raised. But L., standing behind her, is aware of her tension (or just wants to see what the handler is doing) and steps slightly to one side; in so doing, he appears behind Kez in her field of view. She begins to relax and, as he completes the movement (third picture) she turns her head toward him. Only then did her tension reduce. Now, her tail is loose, and her ears are pricked forward, toward L. The rope constrained her, forcing her to put up with the interaction with the unknown handler, yet the invisible connection with her human remained, as a source of comfort. ${ }^{6}$
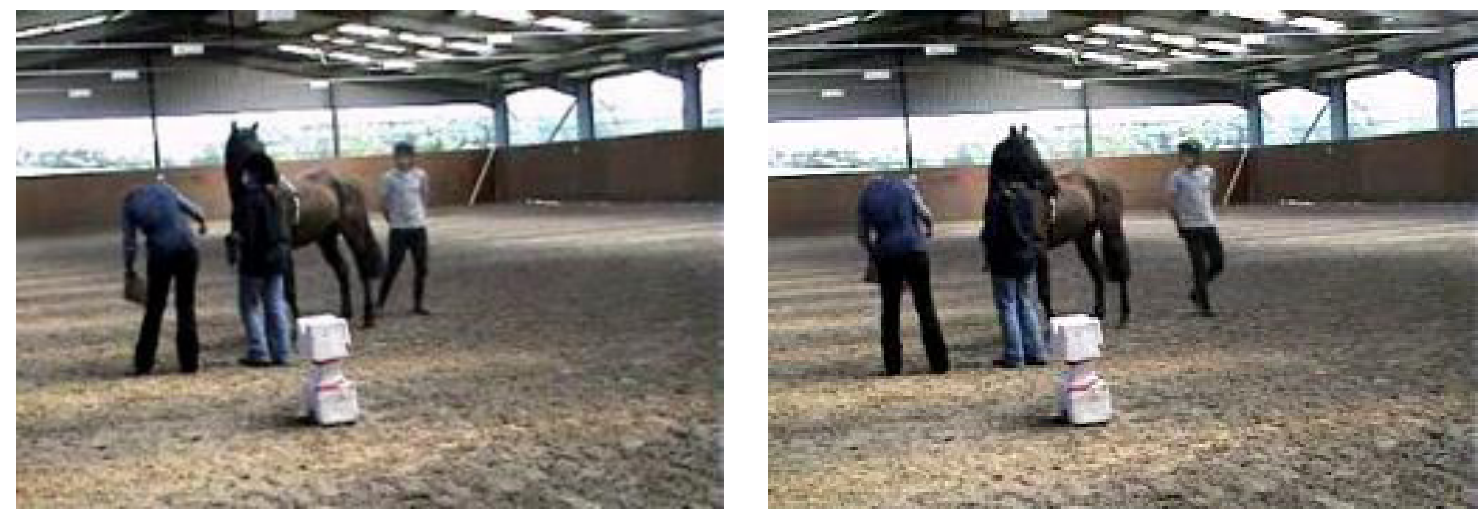

Figure 3: Kez and her human, L., assessing from moment to moment where the other is

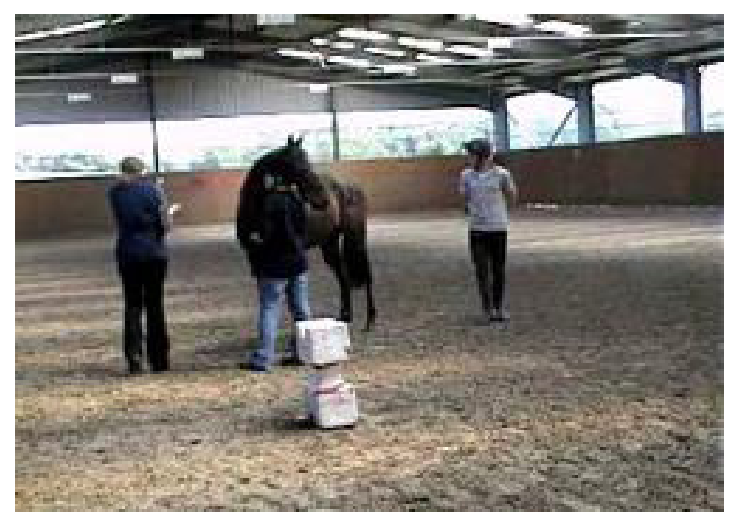

The halter/rope undoubtedly direct movement; rope and human hands offer guidance, and limit resistance. While Kez was handled by someone she did not know, she was tense and uncooperative, although the leadrope provided constraint. Yet, with their

6 These stills are taken from footage taken during our study of horse-human relationships (Birke \& Hockenhull 2015). Kez had previously had a surcingle fitted, carrying a heart rate monitor; here, the researchers are adjusting the monitor before Kez is led away by the unfamiliar handler. She remained tense throughout her encounter with the new person. 
familiar people, both Bill and Kez seemed focused on working alongside their human, seemingly ignoring the restriction of the rope. In these (apparently) simple tasks of leading/being led, negotiating space together is crucial; it is part, and constitutive, of the relationship between the two. Horses, as well as humans, produce this harmony, and, because both are attentive to one another, they seem to flow together, to produce a synchrony (see Argent 2012). If human and animal do not know each other, the flow is interrupted; they are meeting each other at either end of the rope, but do not know how best to read the other, to make the meeting work.

When human and animal develop mutuality, we might say that the halter/rope become the meeting point. Just as my connection to my dogs is not simply dog, then leash, then human, but is perhaps better understood as a kind of temporary hybrid, so too is the connection between handler and horse (see footnote 4). While the four walls of the stable necessarily constrain interactions, the rope controls only intermittently; rather, horse and handler - when cooperating - engage with the other, so that movements of one follow the movements of the other.

The meeting point here is not so much a specific place, but is more a way of coming together, of being with each other and knowing where both are (which Kez's anxiety about her person indicates). As the actual connecting rope comes to matter less over time, so the 'invisible thread' of mutual awareness becomes more crucial. The movements seem choreographed, and the rope serves merely to channel direction; horse and human move forward simultaneously and synchronously. Both are listening to one another, at least most of the time.

\section{Meeting Point Three: In physical contact - riding}

"... when the horse listens to you as a rider and wants to do what you want, like if the horse wants to go in there and get over the jumps, you're halfway there"

(show jumping rider, interview: Thompson \& Birke 2014)

Riding is a deeply embodied experience, for both horse and rider (Smart 2011; Game, 2001). While it can at times be conflictual, or seem that the horse and rider simply do not 'gel', riders usually aspire to relationships with their mounts that are harmonious; this is described as 'feel' between horse and rider (Smart 2011; Brandt 2004). In this

7 Familiar pairs of horses and humans maintain more constant distance between them than unfamiliar pairs. Both are adept at reading the other (Birke \& Hockenhull 2015). 
situation, the interspecies meeting point is corporeal, in the physical contact of being on a horse, and in the tactile communication required. Here, horse and human must pay attention not only to one another's movements, but also to their shared activities. That is, they must pay attention through their bodies, to the movements of the other. But our engagements with them during riding involve moving together, often orienting toward something external and paying shared visual attention to a trail, a jump, a marker. Tack (bridles, harness, saddles) plays a role in shaping how we move together, but so too does the external terrain - the open trails, the obstacles to be overcome in a competition.

In riding, horse and human have to work closely together, to make decisions, to help each other out. In trail riding, for example, crossing different types of unpredictable terrain together enables a shared sense of identity. The horse contributes by making choices about route, or how to move, while for the human, suggest Davis et al. $(2013,74)$, "The horse becomes a strategy for getting into it, travelling over it, and letting it come over you". Negotiating open spaces requires joint decision-making, and constant revision.

For other equestrian sports, the spaces of riding may be more stage-managed, made level, and predictable; dressage or show jumping in enclosed arenas are examples. I will use show jumping - the equestrian pursuit in which I engage - as an example, to explore the idea of riding as meeting. Both the horses and I have reasonable technical skills; we know how to jump and to navigate a course. But, like the rider quoted above, I value horses who know how to help out, to make their own decisions at times, especially if I make a misjudgement. The competition begins at home, when I ask the horses to enter the lorry. As with stables, our encounters here are highly constrained, since the horses must travel in confined spaces, necessarily separated from the humans who are driving. Only occasionally do humans and horses meet within these spaces.

Once mounted at the competition, that elusive 'feel' comes into play, as we prepare. It matters a great deal that I pay close attention to how the horse is feeling and responding. In the arena, it might appear that the horse is simply following the rider's instructions - turn here, jump this, and so on; their movements are constrained by the available space, and the demands of the task. Yet here too horses' own agency plays a significant part. Horses must themselves make different judgements of space and movement, which can help, or hinder, the joint effort. In riding, horse and rider must pay close attention to each other, but both must also focus on something external - in this case, the course of jumps. Horses, as well as riders, need to judge the height and width of the obstacle, light and shade. Figure 4 illustrates the focus of the horse (and 
rider) during approach to a jump; ears and eyes are on the fence, as minor adjustments to position and speed are made. They must still have considerable awareness of each other, but also of the task in hand. This kind of obstacle, moreover, creates a bold visual effect, with the spaces beneath, which some horses dislike; to jump this, horse and rider must also trust.

Figure 4: approaching a jump; both horse ('Tiger') and rider focus on the fence ahead

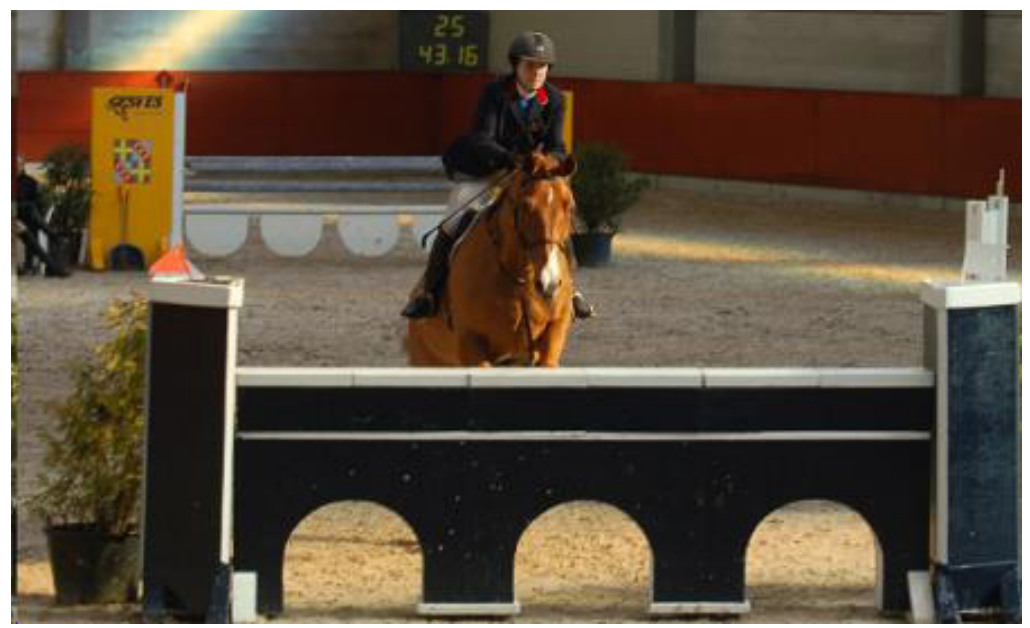

Such competitions entail humans and horses negotiating their conjoint movements in specific ways, as moving over or through obstacles. They require specific skills, not only in terms of riding techniques, but also of spatial judgements: how many strides do we fit into that space between jumps? How do we achieve that? How do we make that turn? How fast can we risk going with that slope? We cannot know how horses directly experience these endeavours, although horse people commonly speak of particular horses as 'loving the buzz' of competitions. The animals do, however, learn over time how to participate, and contribute their judgement to the shared activity, to develop the apparent mutuality so important to horse-riders.

The meeting point of riding entails close, tactile, connection, an understanding of how the other feels as a bodily being. Yet it also involves mobility, as horse and rider engage in a mutual practice, and their attention to each other flows outward to include the task at hand. At its best, this can produce considerable harmony - as is evident in the performance of Olympic dressage stars such as Valegro and his rider Charlotte Dujardin; not for nothing did the newspapers describe the dressage as 'dancing horses'. Horses, of course, take part in these activities at the behest of humans. Perhaps Valegro would have preferred to be eating grass to dancing in front of huge crowds. But horses do engage with us in these shared tasks; they contribute their agency and judgement, and seem, sometimes, to get something out of what they do. Competing is thus not only a meeting point, but a meeting of minds. 


\section{Trajectories}

Meetings, whether in the stable, on the lead rope, or under saddle, involve learning to move together and in relation to one another, and form the basis of human-horse relatings. If the meeting point of the stable focuses their attention on one another by default, the connection between horse and person can become more focused on each other once they emerge from within those four walls. Once outside, the connection is less bounded, and is sometimes apparent without any direct connection. Kez's human partner, L., described for example how he would wander around the arena with Kez loose; yet she would choose to follow him, always being by his side.

My point here is to suggest that the patterns of movement around each other begun within confined spaces create ways of being with each other, patterns of paying attention to the other, which continue into other activities. Horses who are being led from the ground have (usually) learned to adapt their ways of moving to humans, so that what appears at first sight as humans leading plodding and acquiescent horses reflects close coordination and mutual awareness. They meet in each other's space, rather than in physically boundaried places. Taken further, some horsepeople train their horses in 'liberty work' on the ground, in which horse and person move with each other but with no form of restraint at all, just as Kez did.

I have focused here on the idea of meeting, a notion which implies agency. When I watched Kez interacting with her human, for example, her agency seemed apparent. Yet we often encounter horses within human-made structures, which produce a spatiotemporal ordering of both movements and bodies. Writing about humans sharing public space in the course of countryside pursuits such as cycling or walking, Brown (2012, 804) suggests (following Edensor 2010), that such patterns serve as "conduits through which power is exerted, which can help us understand in more detail how bodies are allowed to move in relation to other bodies". Movements around stable yards are not random; bodies of horses and people are monitored, allowed to move in certain ways, to fit human schedules and what is considered 'best practice' (leading the horse so that the animal's head is by your shoulder is, for example, taught as optimal practice in terms of control). In that sense, horses' agency is curtailed or managed. As Cudworth (2011) acknowledges, human relations with animals always involve differential power, and sometimes overt exploitation. But even within that, she argues, there are some possibilities of affection or agency.

If we acknowledge that horses and people can 'work together' with agency through their various shared activities, then what are the implications? In her study of 
people sharing countryside space, Brown $(2012,817)$ suggests that a challenge is then "to cultivate sociomaterial spaces and times that engender more attunement, especially if mere proximity does not equate with meaningful contact". While recognition of equine agency is relatively common in equestrian cultures, as noted above, this is not made explicit in the way that human-equine encounters and performances are staged. Following Brown's suggestion into the horsey realm, perhaps we might consider how, or indeed whether, interspecies encounters in stable yard or competition might be managed to "cultivate more attunement" of horse and rider.

However and wherever they occur, meetings change participants. Each encounter reconstitutes the relationship, so that the movements around each other in open spaces re-produce and shape those within the stable. Pink (2011) uses the idea of 'emplacement' to discuss performative contexts; in her paper, she uses the example of bullfighting, to emphasise that the body of the bullfighter is "one that knows and learns in movement, feeling/sensing her or his way as part of an environment where it 'becomes' in relation to other elements of the arena-as-place-event" (ibid., 354). The movement of human and bull are processes; as such, no one experience of the ring nor meeting with bull - is the same as another; there is no going back. So, too, for horses and people: each time they work/move together is a process of becoming, which produces anew the relationship within its wider environment. That re-enactment may partly consolidate 'conduits of power'; but it can also open channels of becoming.

This mutual becoming might also be described as 'co-being' in our relationship with animals (such as horses, see Maurstad et al. 2013; Game 2001; or dogs, Haraway 2008). While moments of co-being may be experienced anywhere (and especially during riding), they are born in moment-to-moment interactions, various fleeting meetings. The meeting point here is in their physical connection, a kind of intercorporeality, which flows into their actions and shapes their joint responses to the world around. In shared endeavours, there is no longer separated agency of horse and human, but one of conjoint action.

Yet for all that horse people extol feelings of 'oneness' and 'hybridity' with the horse, they - and the horses - can also separate out. Meetings are not always peaceful, and connections can be partial (see Latimer 2013). Even within the confines of a stable or a round pen, horses can make it plain that they do not wish to interact (see Schuurman \& Franklin 2015). Riders often speak of ways in which their animals may express themselves, perhaps even 'being cheeky', not always behaving in as docile a fashion as riders might like (Birke \& Hockenhull 2016; also see Latimer \& Birke 2009). As horses thus 'push the boundaries' they remain other, not always at one with their human. 
Connections and disconnections are made and remade within a relationship, within the daily activities in which human and animal engage as they move through the world. Meetings are sometimes unions, sometimes fragmented. But whatever their form, the horse is part of the process, someone who can engage, or choose to ignore: I invoke the idea of meeting points here because it stresses the horse's agency, as a contributor to the mutual adjustments that make up the relationship and determine the choreography. This trajectory begins with the initial approach in the stable in the morning - hello, how are you? It continues with the subtle adjustments made from moment to moment while walking - where are you? If I move left, will you follow? And it continues with the bodily connection of riding, in which conjoint actions matter - if we move left, how will we tackle what is in front of us? The horse participates in, and produces, these encounters. To speak of a trajectory is also to acknowledge time and experience. Horses certainly participate in interactions from moment-to-moment: but they, just as much as humans, bring to those encounters their own rich histories. These are not casual encounters, but meetings, born out of individual histories that produce the mindedness of the horse. These are meetings, not just with 'a horse', but with someone.

\section{ACKNOWLEDGEMENTS}

I would like to thank Kirrilly Thompson and Jo Hockenhull for discussions and comments on these ideas at earlier stages, and the two anonymous referees for useful comments. Some of the paper is based on research done with Jo Hockenhull and Tami Young. Most of all, I am eternally grateful to the many horses whom I have had the privilege of meeting and knowing. They have taught me to 'feel', and they try to get me to understand. Occasionally I think they have succeeded. 


\section{REFERENCES}

Albuquerque, N., K. Guo, A. Wilkinson, C. Savall, E. Otta, and D. Mills. 2016. Dogs recognize dog and human emotions. Biology Letters 12: 20150883 [accessed online, March 2016]

Argent, G. 2012. Toward a Privileging of the Nonverbal: Communication, Corporeal Synchrony, and Transcendence in Humans and Horses. In: J. A. Smith and R. W. Mitchell (eds.) Experiencing Animal Minds: An Anthology of Animal-Human Encounters. New York: Columbia, pp 111-128.

Armstrong Oma, K. 2013. Human-Animal Meeting Points: Use of Space in the Household Arena in Past Societies. Society \& Animals 21, 162-177

Birke, L. 2008. Talking about Horses: Control and Freedom in the World of "Natural Horsemanship". Society \& Animals 16 (2), 107-126.

Birke, L. and M. Michael. 1997. Hybrids, Rights and their Proliferation. Animal Issues 2, 48-56.

Birke, L. and J. Hockenhull. 2015. Journeys Together: horses and humans in partnership. Society and Animals 23, $81-100$.

2016. Moving with(in) Affect. In: Animals, Space and Affect, ed. N. Schuurman and J. Nyman. London: Routledge.

Brandt, K. 2004. "A Language of Their Own": An Interactionist Approach to Human-Horse Communication." Society and Animals 12 (4): 299-316.

Brown, K. M. 2012. Sharing public space across difference:attunement and the contested burdens of choreographing encounter. Social \& Cultural Geography, 13 (7), 801-820

Cudworth, E. 2011. Social Lives with other Animals: tales of sex, death and love. Basingstoke: Palgrave Macmillan.

Davis, D., A. Maurstad, and C. Cowles. 2013. "Riding up forested mountain sides, in wide open spaces, and with walls": developing an ecology of horse-human relationships. Humanimalia 4(2). Published online.

Edensor, T. 2010. Introduction: thinking about rhythm and space. In: Edensor, T. (ed.) Geographies of Rhythm: Nature, Place, Mobilities and Bodies. Surrey: Ashgate, pp. $1-18$.

Game, A. 2000. Riding: embodying the centaur. Body and Society 7, 1-12.

Haraway, D. 2008. When Species Meet. Minneapolis: University of Minnesota Press.

Holmberg, T. 2015. Urban Animals: Crowding in Zoocities. Abingdon, Oxon: Routledge. 
Latimer, J. 2013. Being Alongside: Rethinking Relations amongst Different Kinds. Theory, Culture, Society 30 (7/8), 77-104.

Latimer J. and L. Birke. 2009. Natural relations: Horses, knowledge and technology. The Sociological Review 57(1): 1-27.

Lefebvre, H. 1991. The Production of Space. Oxford: Blackwell.

Maurstad, A., D. Davis, and S. Cowles. 2013. Co-being and intra-action in horse-human relationships: a multi-species ethnography of be(com)ing human and be(com)ing horse. Social Anthropology 21, 322-335.

McShane, C. and J. A. Tarr. 2007. The Horse in the City: Living Machines in the Nineteenth Century. Baltimore: Johns Hopkins University Press.

Morris, E. 2007. From Horse Power to Horsepower. Access 30, 2-9.

Pink, S. 2011. From embodiment to emplacement: re-thinking competing bodies, senses and spatialities. Sport, Education and Society, 16:3, 343-355

Roberts, M., 1997. The Man Who Listens to Horses. London: Arrow Books.

Rochais, C., S. Henry, C. Sankey, F. Nassur, A. Góracka-Bruzda, and M. Hausberger. 2014. Visual attention, an indicator of human-animal relationships? A study of domestic horses (Equus caballus). Frontiers in Psychology 5, 1-10.

Schuurman, N. and A. Franklin. 2015. Performing expertise in human-animal relationships: performative instability and the role of counterperformance Environment and Planning D: Society and Space, 33, 20-34.

Smart, C. 2011. Ways of Knowing: crossing species boundaries. Methodological Innovations Online 6(3) 27-38.

Smith, A. V., L. Proops, K. Grounds, J. Wathan, and K. McComb. 2016. Functionally relevant responses to human facial expressions of emotion in the domestic horse (Equus caballus). Biology Letters. 12: 20150907 [accessed online, March 2016]

Thompson, K. and L. Birke. 2014. "The horse has got to want to help": human-animal habituses and networks of relationality in amateur show jumping. In: J. Gillett and M.Gilbert (eds.), Sport, Animals and Society. New York: Routledge. 